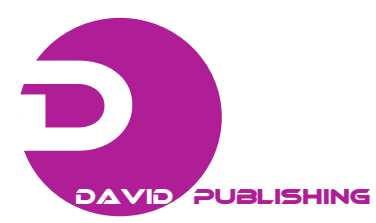

\title{
Industrial Effluents Assessment and Management for Better Crop Production
}

\author{
Golum Kibria Muhammad Mustafizur Rahman*, Zebunnesa, Mohammad Rafiqul Islam, Mohammad Mizanur \\ Rahman and Abdul Mannan Akanda \\ Department of Soil Science, Bangabandhu Sheikh Mujibur Rahman Agricultural University (BSMRAU), Gazipur 1706, Bangladesh \\ *Corresponding author's e-mail: mustafiz@bsmrau.edu.bd
}

\begin{abstract}
Heavy metals in industrial effluents are huge concern among the academician, researchers, general people, media personnel and policy makers. Therefore, a study was carried out to assess the quality of industrial effluents; evaluate the impact of effluents on rice production and soil chemical properties; and manage the industrial effluents through bioremediation. The substantial amounts of most of the heavy metals ( $\mathrm{Fe}, \mathrm{Mn}, \mathrm{Zn}, \mathrm{Cu}, \mathrm{Pb}, \mathrm{Cd}, \mathrm{Cr}$ and $\mathrm{Ni}$ ) were detected in industrial effluents and also in different grid soils of contaminated command area as compared to control grid, where industrial effluent could not reach. Though, the amounts of heavy metals contained in contaminated soils were not beyond the maximum permissible limit (US Environmental Protection Agency Part 503 regulations), but exerted toxic effect on the yield of rice. The concentrations of heavy metals in rice grains were still below the maximum levels as stipulated by the Malaysian Food Act (1983) and Food Regulations (1985). An investigation was also carried out to evaluate the feasibility of bioremediation of industrial effluents contaminated soils by Trichoderma suspended solution and Trichoderma enriched compost. Satisfactory growth of bacteria and fungi were observed in culture media and availability of toxic metal was reduced in contaminated soils. The reduction of heavy metals was reflected in removal of their availability in treated soil. Significant change was achieved after imposing treatment in contaminated soil. Decreasing trends of the availability of heavy metals clearly confirmed the efficacy of bioremediation through Trichoderma suspended solution and Trichoderma enriched compost. The judicious remediation of heavy metals of industrial effluent contaminated soil with soil microorganisms is a sound practice for industrial effluents management and using as a healthy organic fertilizer for improving soil health and better crop production.
\end{abstract}

Key words: Heavy metals, industrial effluents, rice production and soil chemical properties, bioremediation. 